\title{
Targeted Observations with an Airborne Wind Lidar
}

\author{
M. Weissmann, R. Busen, A. Dörnbrack, S. Rahm, and O. Reitebuch \\ Institut für Physik der Atmosphäre, DLR Oberpfaffenhofen, Wessling, Germany
}

(Manuscript received 3 December 2004, in final form 1 April 2005)

\begin{abstract}
This study investigates the possibilities and limitations of airborne Doppler lidar for adaptive observations over the Atlantic Ocean. For the first time, a scanning 2- $\mu \mathrm{m}$ Doppler lidar was applied for targeted measurements during the Atlantic "The Observing System Research and Predictability Experiment" (THORPEX) Regional Campaign (A-TReC) in November and December 2003. The DLR lidar system was operated for 28.5 flight hours, and measured 1612 vertical profiles of wind direction and wind speed with a horizontal and vertical resolution of 5-10 km and $100 \mathrm{~m}$, respectively. On average, there were 25 reliable wind values on every profile, which cover $2500 \mathrm{~m}$ in the vertical (about one-third of the mean vertical extent of the profiles). A statistical comparison of 33 dropsondes and collocated lidar winds profiles allowed individual estimates of the standard deviation to be assigned to every wind value and to determine threshold values for an objective quality control of the data. The standard deviation of the difference between dropsonde and lidar winds was correlated with the derived quality indices of the lidar data and was within a range of $0.6-1.8 \mathrm{~m} \mathrm{~s}^{-1}$. Comparisons of the lidar data to the operational analysis revealed differences of up to $\pm 15 \mathrm{~m} \mathrm{~s}^{-1}$. This emphasizes the need for more representative and higher resolved wind measurements in data-sparse regions above the Atlantic Ocean. The study constitutes the basis for the assimilation of the lidar data and impact studies at the European Centre for Medium-Range Weather Forecasts (ECMWF).
\end{abstract}

\section{Introduction}

A significant component of forecast errors of numerical weather prediction (NWP) models arises from uncertainty in the initial conditions. Adaptive observational techniques (targeting) are expected to reduce this error by improving the initial state (i.e., the analysis) of the NWP models. These measurements are performed in sensitive regions: predicted areas where small uncertainties of the initial state grow quickly and result in a large impact on the forecast skill in spatially distinct verification regions.

Targeted observations have been utilized in previous field campaigns, starting with the Fronts and Atlantic Storm Track Experiment (FASTEX) in 1997 (Joly et al. 1997, 1999). The first systematic targeting was applied during the 1999 and 2000 Winter Storm Reconnaissance Programs (WSR99 and WSR00, respectively; Szunyogh et al. 2000, 2002) during the North Pacific

Corresponding author address: Martin Weissmann, Deutsches Zentrum für Luft- und Raumfahrt (DLR), Institut für Physik der Atmosphäre, D-82230 Wessling, Germany.

E-mail: martin.weissmann@dlr.de
Experiment (NORPEX; Langland et al. 1999). In these experiments, the 1-3-day forecast error in regional verification areas was reduced by about $10 \%-20 \%$ (Montani et al. 1999; Langland et al. 1999; Szunyogh et al. 2000, 2002). Based on the encouraging results of the Pacific experiments, a field campaign over the Atlantic Ocean was conducted in November and December 2003 [the Atlantic "The Observing System Research and Predictability Experiment" (THORPEX) Regional Campaign (ATReC; information available online http://www.wmo.int/thorpex/)].

Several observational platforms were deployed adaptively during A-TreC, including dropsondes launched from research aircrafts, Aircraft Meteorological Data Reporting (AMDAR), Automated Shipboard Aerological Program (ASAP), radiosondes, drifting buoys, and satellite rapid-scan winds. In addition to these sensors, an airborne Doppler lidar system was deployed for targeted observations for the first time.

The intention was to test the capability of Doppler lidars to sample sensitive areas. For this purpose, a $2-\mu \mathrm{m}$ scanning Doppler lidar was operated simultaneously with a dropsonde system on board the Deutsches Zentrum für Luft- und Raumfahrt (DLR) Falcon research aircraft. Based on a climatology of sensitive re- 
gions for severe European weather events (Marseille and Bouttier 2001), the aircraft was based in Keflavik, Iceland. It was an open question as to whether the lidar instrument is a valuable tool for targeted wind observations above the northern Atlantic Ocean. Problems for coherent lidar observations in this region are clouds on one side, and the low aerosol concentrations on the other. However, the autumnal cold-air outbreaks that are associated with strong surface winds over the warm ocean lead to broken cumulus convection, increased humidity, and an enhanced sea-salt aerosol load.

This study discusses the accuracy and the data coverage of the lidar observations during A-TReC. We investigate the observational error of the lidar wind measurements through a statistical intercomparison with dropsonde profiles. Based on this comparison, quality indices and their threshold values are derived. We assign individual estimates of the standard deviation for different classes of the quality indices. These values serve as important input parameters for the assimilation schemes of NWP models. Different processing algorithms are tested to calculate the horizontal wind from line-of-sight (LOS) measurements. We compare their accuracy and spatial coverage, and we demonstrate possible improvements with a reduction of the horizontal resolution (averaging of several scanner revolutions). Reference values for the data coverage are classified for different values of background humidity and as function of the distance from the aircraft. Furthermore, the study describes the lidar performance under different meteorological conditions.

Airborne Doppler lidars have been used in several case studies of mesoscale phenomena, such as the French mistral (Drobinski et al. 2005), Alpine foehn (Reitebuch et al. 2003), the sea breeze in southern France (Bastin et al. 2005), or the Alpine mountainplain circulation (Weissmann et al. 2005). So far, airborne Doppler lidar measurements have never been assimilated in an NWP model. The current investigations constitute the basis for the assimilation of the lidar data and impact studies at the European Centre for Medium-Range Weather Forecasts (ECMWF).

After this introduction, section 2 describes the Doppler lidar and the dropsonde system, section 3 gives an intercomparison of dropsonde and lidar data, and section 4 discusses the characteristics of the lidar measurements during A-TReC. Finally, the conclusions of the paper and an outlook are presented in section 5.

\section{The Doppler lidar and dropsonde systems}

The system measures vertical profiles of the threedimensional wind vector $\mathbf{V}=(u, v, w)$ beneath the
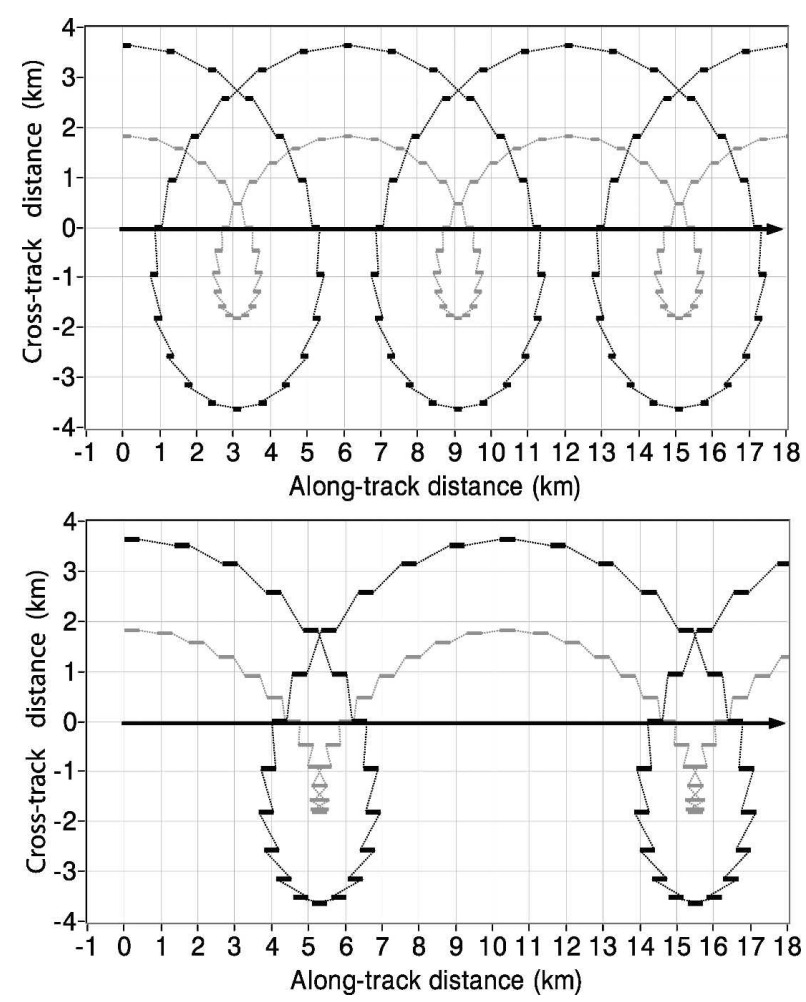

FIG. 1. Scan pattern at 5- (gray) and 10- (black) km distance beneath the aircraft with an accumulation time of (top) 1 and (bottom) $2 \mathrm{~s}$; measurement segments (solid lines), scanner motion from one position to the next (dashed lines), and aircraft flight track (arrows). The flight level for the calculation was $10 \mathrm{~km}$, and the aircraft ground speed was $200 \mathrm{~m} \mathrm{~s}^{-1}$.

aircraft. The wind profiles are retrieved from LOS measurements of the Doppler lidar by the velocity-azimuth display (VAD) technique (Browning and Wexler 1968; Smalikho 2003). The instrument performs a conical step-and-stare scan around the vertical axis with a nadir angle of $20^{\circ}$. Combined with the movement of the aircraft, this results in a cycloid scan pattern (Fig. 1). The horizontal resolution of the wind profiles $(5-10 \mathrm{~km})$ is determined by the time needed for one scanner revolution (24 times 1 or $2 \mathrm{~s}$ as accumulation time per scan position, plus $6 \mathrm{~s}$ for the scanner motion) and the aircraft velocity $\left(160-240 \mathrm{~m} \mathrm{~s}^{-1}\right)$. The vertical resolution of $100 \mathrm{~m}$ is determined by the pulse length of the laser [full width at half maximum (FWHM) $=400 \mathrm{~ns}(\sim 120$ $\mathrm{m})$ ] and the nadir angle of $20^{\circ}$.

The main component is a transceiver developed by Coherent Technologies, Inc. (CTI; Henderson et al. 1993). It consists of a diode-pumped continuous wave (CW) master laser, and a pulsed slave laser (Table 1; Köpp et al. 2004). The master laser is characterized by a single-frequency operation and a low bandwidth to 
TABLE 1. Main parameters of the lidar system.

\begin{tabular}{ll}
\hline \hline Slave laser & Tm:LuAG (pulsed) \\
Wavelength & $2.02254 \mu \mathrm{m}$ \\
Energy & $1.5 \mathrm{~mJ}$ \\
Pulse length & $400 \mathrm{~ns}$ FWHM $(\sim 120 \mathrm{~m})$ \\
Repetition rate & $500 \mathrm{~Hz}$ \\
Frequency offset & $102 \pm 3 \mathrm{MHz}$ \\
Master laser & Tm:LuAG $(\mathrm{CW})$ \\
Telescope diameter & $108 \mathrm{~mm}$ \\
Power $\times$ aperture & $6 \mathrm{~m} \mathrm{~W} \mathrm{~m}{ }^{-2}$ \\
Scanner & Rotating silicon wedge \\
Nadir angle & $20^{\circ}$ \\
Vertical resolution & $100 \mathrm{~m}$ \\
Horizontal resolution of wind & $\sim 5-10 \mathrm{~km}$ \\
$\quad$ profiles & \\
Time for one scanner revolution & 30 or $54 \mathrm{~s}$ \\
Scan positions on one revolution & 24 \\
Accumulation time at every & 1 or $2 \mathrm{~s}$ \\
$\quad$ position & \\
Accumulated pulses at every & 500 or 1000 \\
$\quad$ position & \\
Aircraft velocity & $160-240 \mathrm{~m} \mathrm{~s}{ }^{-1}$ \\
Data acquisition & Every single shot \\
Sampling frequency & $500 \mathrm{MHz}$ \\
Data volume & $\sim 1 \mathrm{~GB}\left(\mathrm{~min}^{-1}\right.$ \\
Range & $0.5-12 \mathrm{~km}^{-1}$ \\
\hline
\end{tabular}

provide high heterodyne efficiency. It is used for the injection seeding of the slave laser and as a local oscillator for the coherent detection. The signal from the pulsed slave laser is transmitted into the atmosphere. The operation in an atmospheric window at 2.02254 $\mu \mathrm{m}$, with low absorption by water vapor, allows for an eye-safe operation and wind measurements up to a range of $12 \mathrm{~km}$ despite the low pulse energy of $1.5 \mathrm{~mJ}$.

The data acquisition and recording unit was designed by DLR (Rahm et al. 2003). The analog heterodyne signal that is measured at the detector is amplified with an adjustable gain of 30-70 $\mathrm{dB}$ and a bandwidth of 1 $\mathrm{GHz}$. The signal from every single shot and the reference signal from the pulse-monitor detector are stored.

One advantage of the $2-\mu \mathrm{m}$ system is the repetition rate of $500 \mathrm{~Hz}$, compared to $10 \mathrm{~Hz}$ for the Wind Infrared Doppler Lidar (WIND) system (Reitebuch et al. 2001). As a consequence, 500 or 1000 pulses are accumulated at every scanner position, reducing the speckle noise. Furthermore, the $2-\mu \mathrm{m}$ laser signal has a nearGaussian shape in the spatial, temporal, and spectral domain, which reduces the uncertainty of the Doppler estimates.

Two different algorithms are applied to calculate $\mathbf{V}$. The first one is based on the maximum function of accumulated spectra (MFAS; Smalikho 2003). All spectra from the 24 scan positions are accumulated after shifting them to be proportional to their azimuth angle and a hypothetical wind. This procedure is repeated for every possible horizontal wind speed and direction. If the hypothetical wind matches the real wind, the accumulated spectrum shows an intensity maximum. The ratio of the intensity at (and near) the maximum to the cumulative intensity at all of the other hypothetical winds (called intensity ratio in the following) acts as one quality criterion for the wind estimate. An intensity ratio of about $6: 1$ is the minimum for an acceptable wind calculation. For a strong lidar signal and a small horizontal variability of the observed wind field, the intensity ratio is around 20:1. The spectral width of the maximum accumulated spectrum (called spectral width in the following) is a second quality criterion. A broad maximum indicates a large uncertainty of the wind estimate or atmospheric turbulence.

The other algorithm (inversion) calculates the spectral peak and the frequency shift (LOS velocity) for the heterodyne signal at every scanning position using a peak finder. The 24 LOS velocities are grouped in three $120^{\circ}$ sectors, and eight different wind vectors are calculated using one LOS velocity from each group, respectively. Afterward, all eight vectors are averaged. LOS values that do not agree with the resulting wind vector are eliminated, and a new wind vector is calculated with the remaining LOS velocities. This procedure is repeated until all of the LOS velocities match the wind vector within a tolerance range of $\pm 1 \mathrm{~m} \mathrm{~s}^{-1}$ during A-TReC. The percentage of LOS velocities that is used for the calculation of the final wind vector (called percentage LOS in the following) is a quality criterion for the data.

Both algorithms can also be applied to derive $\mathbf{V}$ from more or less than 24 LOS velocities. During A-TReC the calculation of $\mathbf{V}$ profiles from four scanner revolutions was used additionally with the wind calculation from one scanner revolution to increase the coverage with reliable wind data in case of a low heterodyne signal: 96 spectra were accumulated in the MFAS algorithm and 96 LOS velocities were inverted in the inversion algorithm in the same way as for one scanner revolution.

The inversion algorithm is rather selective because it ignores all values that do not fit the mean wind. The MFAS, on the other hand, accumulates all spectra. For this reason the MFAS algorithm is assumed to be more reliable for the wind calculation from several scanner revolutions.

The aircraft attitude angles (roll, pitch, and heading) are measured with an inertial reference system (IRS), and the velocity is obtained by the global positioning 
TABLE 2. The standard deviations $\sigma_{\mathrm{wspd}}, \sigma_{u}, \sigma_{v}, \sigma_{\mathrm{wdir}}$, and the bias of the wind speed for lidar winds derived with the MFAS and with the inversion algorithm. The relative numbers were calculated with respect to the mean wind speed and wind components. The bracketed values of $\sigma_{v}$ were derived with the manual exclusion of three outliers.

\begin{tabular}{lcccrr}
\hline & $\sigma_{\text {wspd }}$ & \multicolumn{1}{c}{$\sigma_{u}$} & $\sigma_{v}$ & $\sigma_{\text {wdir }}$ & Bias wind speed \\
\hline Inversion & $1.20 \mathrm{~m} \mathrm{~s}^{-1} 4.4 \%$ & $1.16 \mathrm{~m} \mathrm{~s}^{-1} 4.7 \%$ & $1.20 \mathrm{~m} \mathrm{~s}^{-1} 1.2 \%$ & $3.62^{\circ}$ & $0.004 \mathrm{~m} \mathrm{~s}^{-1} 0.0 \%$ \\
MFAS & $1.04 \mathrm{~m} \mathrm{~s}^{-1} 3.5 \%$ & $1.01 \mathrm{~m} \mathrm{~s}^{-1} 3.7 \%$ & $1.2(1.04) \mathrm{m} \mathrm{s}^{-1} 12.1 \%(10.5 \%)$ & $3.64^{\circ}$ & $-0.31 \mathrm{~m} \mathrm{~s}^{-1} 1.0 \%$ \\
\hline
\end{tabular}

system (GPS). The specification of the GPS receiver assures an accuracy of better than $0.1 \mathrm{~m} \mathrm{~s}^{-1}$. The comparison of the velocity of the ground return that was measured by the lidar and the GPS velocity showed a similar accuracy. Over land, the attitude angles can be calibrated with the speed of the ground return, which should be equal to zero. During A-TReC, this calibration was performed once or twice per flight because most of the flights took place over the Atlantic Ocean. A calibration with the water return is not possible because the albedo is too low and the velocity of the water is not zero. Above continents, the lidar observations can be calibrated continuously, which increases the accuracy of the wind observations. A continuous calibration seems to be obligatory for reasonable measurements of the vertical velocity (Weissmann et al. 2005). Thus, observations of vertical motions during A-TReC are not discussed in this study.

Additionally, 49 standard GPS dropsondes RD93 (Väisäla) were deployed to measure temperature, humidity, pressure, and wind. Six dropsondes could not be tracked by the GPS receiver. Thus, only 43 sondes provided wind information. Their vertical resolution amounts to $10 \mathrm{~m}$, and the accuracy of horizontal wind speed is $\pm 0.5 \mathrm{~m} \mathrm{~s}^{-1}$.

\section{Statistical comparison of dropsondes and lidar}

The lidar and dropsonde data were compared with each other to derive a representative standard deviation for the lidar winds. These values will represent the observational error in the assimilation scheme of the ECMWF. Previous studies (Reitebuch et al. 2001; Weissmann et al. 2005) were limited to a few profiles, whereas 33 wind profiles could be compared during this campaign. Nine dropsonde wind profiles were excluded, because the lidar signal in the vicinity of the sondes was too weak. One dropsonde was discarded because the wind profile was not representative for the lidar measurements (section 3e).

The horizontal distance between the dropsondes and the center of the corresponding lidar profiles ranged from 0 to $23 \mathrm{~km}$; the mean distance amounted to $6.5 \mathrm{~km}$. Additionally, the horizontal extension of the lidar and dropsonde measurements was different. The lidar profiles were an average over 24 LOS measurements with a horizontal extension of up to $10 \mathrm{~km}$ (Fig. 1 ), whereas the horizontal drift of the dropsonde was in a range of 20-300 m for a vertical fall of $100 \mathrm{~m}$, depending on wind speed and height. The fall rate of the dropsonde was about $10-20 \mathrm{~m} \mathrm{~s}^{-1}$, and the resulting time difference to the lidar measurements was up to 11 $\min$.

Corresponding to every dropsonde profile two lidar wind profiles were calculated with the 24 LOS measurements that were closest to the position of the sonde: one using the MFAS, and another one using inversion algorithm. The dropsonde measurements were vertically averaged over $100 \mathrm{~m}$ to yield a corresponding resolution to the lidar data.

\section{a. Comparison of $\mathbf{V}$ calculated with the inversion algorithm and dropsonde winds}

The application of the inversion algorithm to the lidar LOS measurements resulted in 740 comparable wind vectors $\mathbf{V}$. The standard deviation of the difference of all dropsonde and lidar wind speeds $\left(\sigma_{\mathrm{wspd}}\right)$ for all lidar measurements with a percentage LOS of more than $50 \%$ was $1.2 \mathrm{~m} \mathrm{~s}^{-1}$, and the standard deviations of the difference of the zonal and meridional wind components $\left(\sigma_{u}\right.$ and $\left.\sigma_{v}\right)$ were of the same magnitude, respectively (Table 2). This corresponds to a relative wind speed difference of $4.4 \%$. The difference of lidar and dropsonde winds was correlated neither with the height of the measurements, nor with the wind speed. Because of the fact that zonal wind components are generally stronger than meridional wind components in midlatitudes, the relative error of $v$ was more than twice as high as that of the relative error of $u$. The mean standard deviation of the difference between lidar and dropsonde wind directions $\left(\sigma_{\text {wdir }}\right)$ amounted to $3.6^{\circ}$. Neither the wind speed, the wind components, the magnitude of the wind components, nor the wind direction showed a relevant bias (Table 2).

The percentage LOS proved to be a good quality index for the lidar data that effectively filtered out noise. At least a percentage LOS of $50 \%$ was necessary for reliable lidar winds. All standard deviations de- 

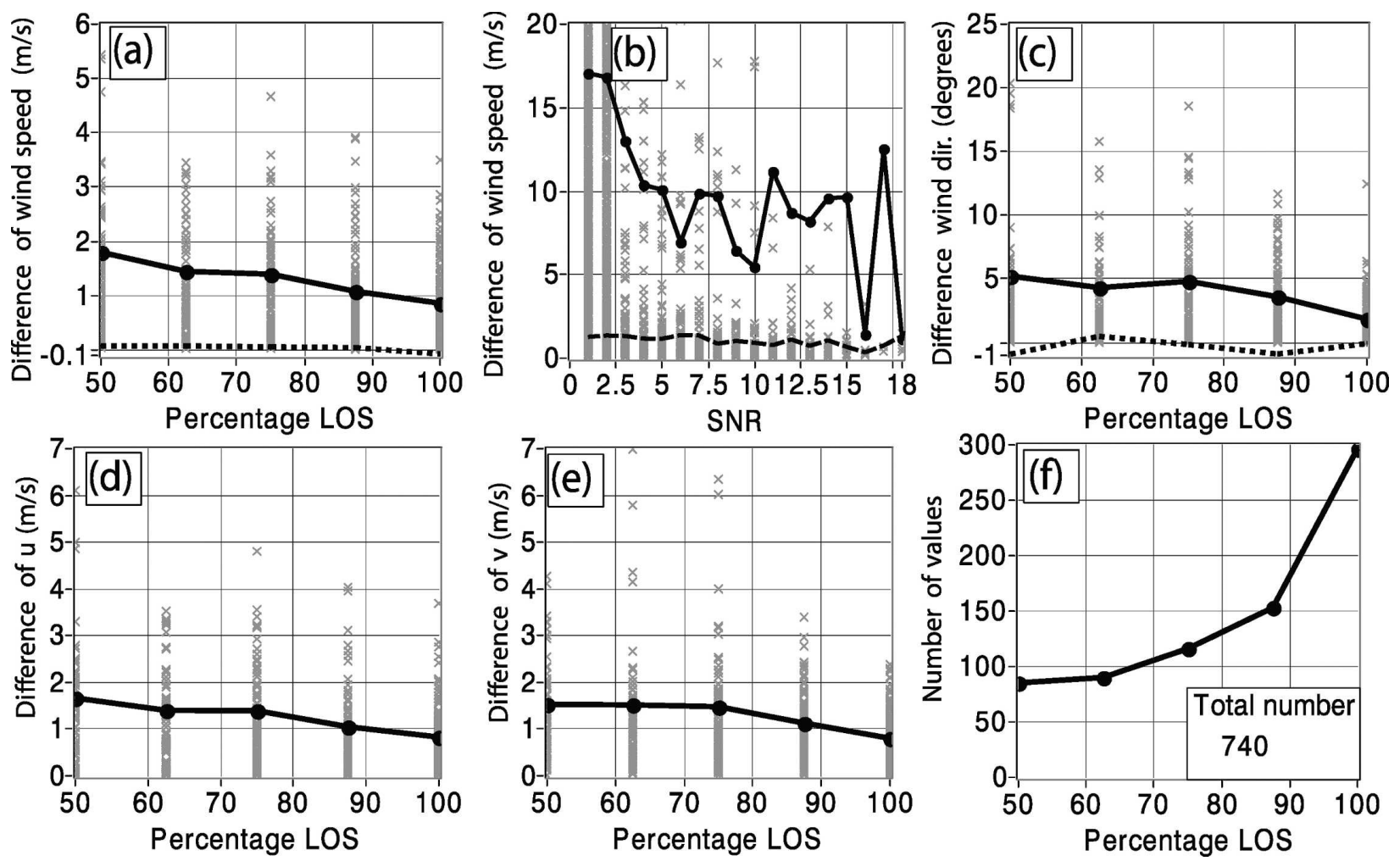

FIG. 2. (a) Gray x symbols mark the absolute value of the difference between lidar and dropsonde wind speeds as function of the percentage LOS of the lidar data; the standard deviation of these differences ( $\sigma_{\text {wspd }}$, black solid line) and the bias (dotted line) are shown. (b) Same as (a), but as a function of the SNR. The standard deviation after a filtering of the lidar data with a minimum percentage LOS of $50 \%$ (dashed line) is shown. (c), (d), (e) Same as (a), but for (c) the wind direction, (d) $u$ component, and (e) $v$ component, respectively. (f) Histogram of the compared winds as function of the percentage LOS.

creased with an increasing percentage LOS (Fig. 2), and individual standard deviations could be assigned to different classes of the quality index. The maximum standard deviations $\sigma_{\text {wspd }}, \sigma_{u}$, and $\sigma_{v}$ were $1.5-1.8 \mathrm{~m} \mathrm{~s}^{-1}$ for a percentage LOS of $50 \%$. For a high percentage LOS, the standard deviations dropped to about $0.8 \mathrm{~m} \mathrm{~s}^{-1}$, and the standard deviation $\sigma_{\text {wdir }}$ decreased to less than $2^{\circ}$.

The standard deviations were also correlated with the signal-to-noise ratio (SNR), but this quality index failed to sort out noise. Figure $2 b$ illustrates the decrease of the wind speed differences (gray " $\mathrm{x}$ " symbols) with an increasing SNR, but outliers cause a large standard deviation $\sigma_{\text {wspd }}$ for all classes of SNR. Thus, the SNR can only be used as quality index for the lidar winds after the data are filtered with a minimum percentage LOS (dashed line in Fig. 2b).

\section{b. Comparison of $\mathbf{V}$ calculated with the MFAS algorithm and dropsonde winds}

The calculation of lidar wind profiles with the MFAS algorithm derived 508 comparable values of V. Two indices were necessary for the quality control of winds derived with the MFAS algorithm: the intensity ratio and the spectral width. The comparison showed that the spectral width should be smaller than 2.3, and the intensity ratio should be larger than 5.9 to derive reliable winds. With the exception of the three erroneous $v$ components, the filtering of the data with a threshold for both indices proved to be an effective quality check.

After the filtering of the lidar data the standard deviation $\sigma_{\text {wdir }}$ of all values amounted to $3.5^{\circ}$, the standard deviation $\sigma_{\mathrm{wspd}}$ was $1.04 \mathrm{~m} \mathrm{~s}^{-1}$, and the relative difference of the wind speed was to $3.5 \%$ (Table 2). A similar value was calculated for the standard deviation $\sigma_{u}$. The standard deviation $\sigma_{v}$ was slightly higher because of the three outliers with differences of 6-9 $\mathrm{m} \mathrm{s}^{-1}$. These outliers are three erroneous values that were not detected by the quality control scheme. If these values were excluded, the standard deviation $\sigma_{v}$ was about the same as $\sigma_{u}$ (Table 2). The existence of these three outliers illustrates that the detection of all erroneous values is a challenge for an objective quality control. In a subjective quality control, however, these values would 
be obvious because they do not agree with the surrounding winds; it is expected that, also, the assimilation schemes of NWP models eliminate these values.

The comparison of dropsonde and lidar wind speeds that are calculated with the MFAS algorithm showed a bias of $-0.31 \mathrm{~m} \mathrm{~s}^{-1}$, that is, the MFAS algorithm underestimated the wind speed by about $1 \%$. The bias correlated with the spectral width (Fig. 3), which is a measure for the noise and atmospheric turbulence. In contrast, there was no correlation with the intensity ratio. The comparison of all wind speeds that are derived with the MFAS and the inversion algorithm also revealed a bias fluctuating between -0.05 and -0.35 $\mathrm{m} \mathrm{s}^{-1}$ on different days (Table 3). The reason for the bias is unclear. Tests with simulated lidar data are planned to investigate this phenomenon. The bias of the wind direction was only $0.5^{\circ}$. This appeared to be less than the uncertainty of the comparison, and, consequently, it was not interpreted as a systematic bias.

The standard deviations $\sigma_{\mathrm{wspd}}, \sigma_{\mathrm{wdir}}, \sigma_{w}$ and $\sigma_{v}$ of the filtered data were correlated with both quality indices of the MFAS algorithm (Fig. 3). The maximum of the standard deviations $\sigma_{\mathrm{wspd}}, \sigma_{\mathrm{u}}$, and $\sigma_{v}$ was about
TABLE 3. Comparison of the lidar winds, calculated with the MFAS and the inversion algorithm. Coverage is the relative fraction of the number of reliable lidar winds of the possible number of measurements. The total coverage is the coverage derived with a combination of both algorithms.

\begin{tabular}{lcccc}
\hline \hline \multicolumn{1}{c}{ Date } & $\begin{array}{c}\text { Coverage } \\
\text { MFAS }\end{array}$ & $\begin{array}{c}\text { Coverage } \\
\text { inversion }\end{array}$ & $\begin{array}{c}\text { Tot } \\
\text { coverage }\end{array}$ & $\begin{array}{c}\text { Difference } \\
\text { (inversion - } \\
\text { MFAS) }\end{array}$ \\
\hline 14 Nov & $31.2 \%$ & $38.5 \%$ & $40.0 \%$ & $0.16 \mathrm{~m} \mathrm{~s}^{-1}$ \\
15 Nov (part 1) & $21.4 \%$ & $24.1 \%$ & $24.6 \%$ & $0.35 \mathrm{~m} \mathrm{~s}^{-1}$ \\
15 Nov (part 2) & $21.9 \%$ & $23.4 \%$ & $25.3 \%$ & $0.32 \mathrm{~m} \mathrm{~s}^{-1}$ \\
18 Nov & $54.0 \%$ & $65.4 \%$ & $66.7 \%$ & $0.05 \mathrm{~m} \mathrm{~s}^{-1}$ \\
20 Nov (part 1) & $10.5 \%$ & $17.3 \%$ & $18.0 \%$ & $0.10 \mathrm{~m} \mathrm{~s}^{-1}$ \\
22 Nov & $22.3 \%$ & $22.0 \%$ & $25.1 \%$ & $0.32 \mathrm{~m} \mathrm{~s}^{-1}$ \\
24 Nov & $43.7 \%$ & $58.8 \%$ & $62.5 \%$ & $0.18 \mathrm{~m} \mathrm{~s}^{-1}$ \\
25 Nov & $28.1 \%$ & $43.4 \%$ & $46.3 \%$ & $0.15 \mathrm{~m} \mathrm{~s}^{-1}$ \\
28 Nov & $9.2 \%$ & $13.9 \%$ & $15.0 \%$ & $0.16 \mathrm{~m} \mathrm{~s}^{-1}$ \\
Average & $26.9 \%$ & $29.4 \%$ & $35.9 \%$ & $0.20 \mathrm{~m} \mathrm{~s}^{-1}$ \\
\hline
\end{tabular}

$1.3 \mathrm{~m} \mathrm{~s}^{-1}$, and the maximum of $\sigma_{\mathrm{wdir}}$ amounted to $6^{\circ}$ (if the three outliers were excluded manually for the calculation of $\sigma_{v}$ ). For a high-quality lidar signal the standard deviations $\sigma_{\mathrm{wspd}}, \sigma_{u}$, and $\sigma_{v}$ dropped to about 0.6 $\mathrm{m} \mathrm{s}^{-1}$, and the standard deviation $\sigma_{\text {wdir }}$ decreased to $1^{\circ}$.
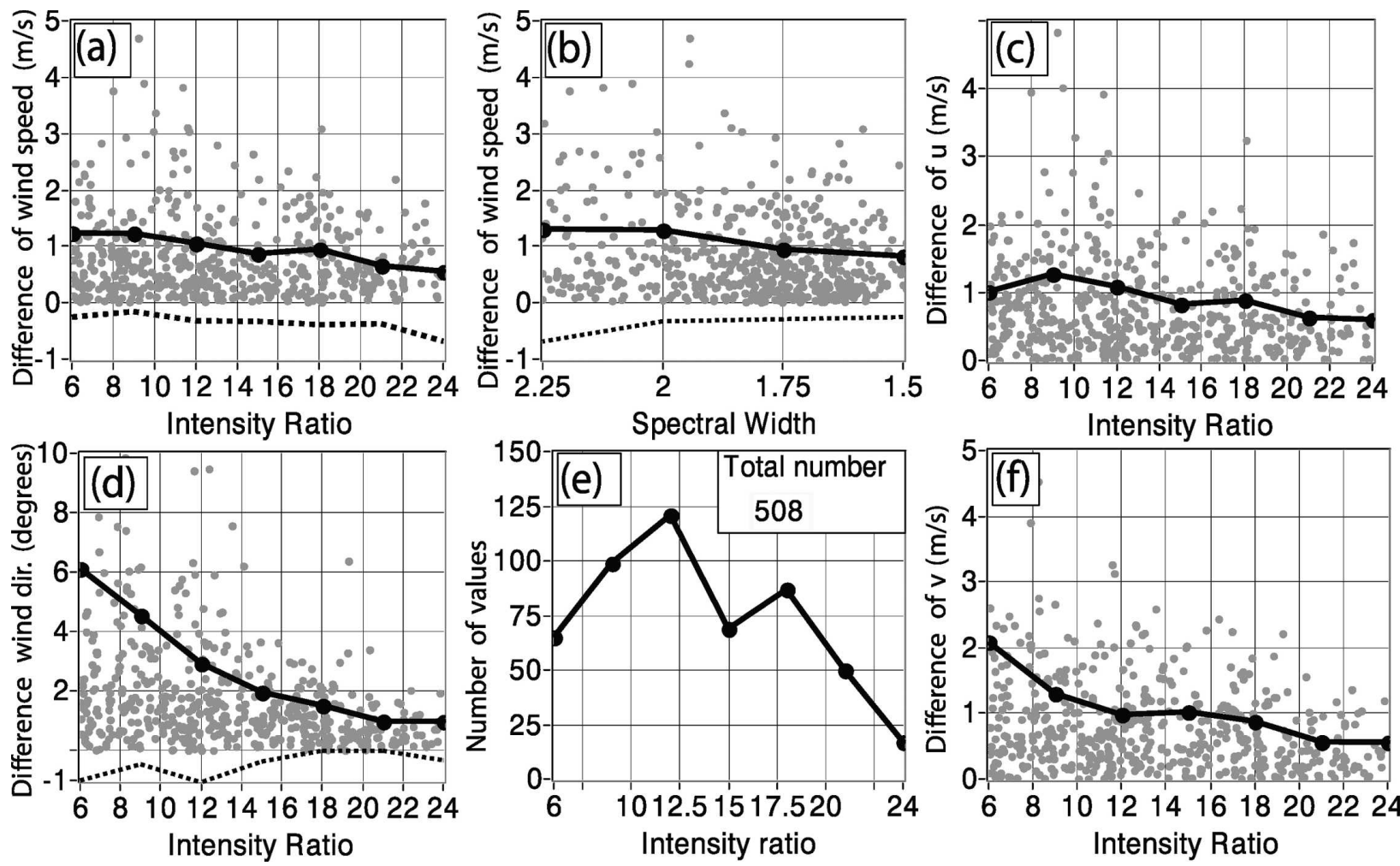

FIG. 3. (a) Gray points mark the absolute value of the difference between lidar and dropsonde wind speeds as function of the intensity ratio. The standard deviation of these differences $\left(\sigma_{\text {wspd }}\right.$, black solid line) and the bias (dashed gray line) are shown. (b) Same as (a), but as function of the spectral width. (c), (d), (f) Same as (a), but for the (c) $u$ component, (d) wind direction, and (f) $v$ component, respectively. (e) Histogram of the compared winds as function of the intensity ratio. 


\section{c. Performance comparison of the MFAS and the inversion algorithms}

In contrast to the results of the theoretical study by Smalikho (2003), the inversion algorithm had a slightly larger coverage (percentage of acceptable winds) than the MFAS algorithm (Table 3). Additionally, the inversion algorithm did not show any bias, whereas the MFAS had a bias of $-0.31 \mathrm{~m} \mathrm{~s}^{-1}$ in the dropsonde comparison. The mean standard deviation was slightly lower with MFAS (Table 2, Figs. 2 and 3), but the MFAS algorithm generated about $30 \%$ less values. In conclusion, the general performance of the inversion algorithm was slightly better than that of the MFAS. Advantageously, it needs only about $10 \%$ of the computational time of the MFAS. Further tests with simulated lidar data are needed to investigate whether the MFAS algorithm can be improved to reach its theoretical performance described by Smalikho (2003).

The best wind retrievals were obtained with a combination of both algorithms (Table 3). Through the comparison of lidar and dropsonde winds (sections 3a, 3b), an individual standard deviation could be assigned to every lidar wind value using the lidar quality indices. In about $60 \%$ of the data, the wind that was calculated with the inversion algorithm possessed the lower standard deviation, and about $40 \%$ of the $\mathbf{V}$ derived with the MFAS algorithm data had a lower standard deviation. Furthermore, the mean coverage of the reliable lidar data could be increased from $27 \%$ with the MFAS and $29 \%$ with the inversion algorithm to $36 \%$ with the combination of both (Table 3 ).

The intercomparison also revealed that the performance of the MFAS and the inversion algorithms varies from day to day (Table 3): while the coverage was about the same for both algorithms on some flights, the inversion algorithm was clearly better on other days. A larger number of observations under different meteorological conditions is necessary to define reliable causal relationships of this day-to-day variability.

\section{d. Distinction between dropsonde error, lidar error, and representativeness error}

Despite the knowledge of the standard deviations $\sigma_{\text {wspd }}, \sigma_{u}$, and $\sigma_{v}$, it is difficult to determine the observational error of the lidar alone. The total variance (squared standard deviation) of the difference of lidar and dropsonde measurements is the sum of the variance resulting from the lidar observational error, the variance resulting from the dropsonde observational error, and the variance caused by the representativeness (sampling) error. This cumulative error is difficult to determine because it depends on the spatial and tem- poral separation of the dropsonde and lidar measurements, the spatial and temporal sampling, and the variability of the wind. A discussion of these effects can be found in three recent papers: Mapes et al. (2003), Frehlich (2001), and Frehlich and Sharman (2004).

The mean representativeness error of the comparison of lidar and dropsonde data during A-TReC was assumed to be similar to the representativeness error of a point measurement in a 9-km grid box, which has a standard deviation of $\sim 0.5 \mathrm{~m} \mathrm{~s}^{-1}$ (variance $\sim 0.25$ $\mathrm{m}^{2} \mathrm{~s}^{-2}$ ) according to the empirical formula of Frehlich and Sharman (2004). The observational error of the dropsondes is also about $0.5 \mathrm{~m} \mathrm{~s}^{-1}$ (variance $\sim 0.25$ $\mathrm{m}^{2} \mathrm{~s}^{-2}$ ).

Assuming these values for the representativeness error and the observational error of the dropsonde, the mean observational standard deviation of the lidar wind speed is about $0.75-1 \mathrm{~m} \mathrm{~s}^{-1}$ (variance $=0.56-1$ $\mathrm{m}^{2} \mathrm{~s}^{-2}$ ), and is roughly the same for both horizontal wind components, respectively. However, for the lidar data with high-quality indices (large percentage LOS, or high intensity ratio and low spectral width), the standard deviation of the lidar is less than $0.5 \mathrm{~m} \mathrm{~s}^{-1}$, based on the same assumptions.

\section{e. Representativity of lidar and dropsonde measurements}

The problem of the representativity of measurements has already been mentioned in section 3d. Several studies documented that the representativeness error often exceeds the observational error in data assimilation schemes (e.g., Mapes et al. 2003; Frehlich 2001; Frehlich and Sharman 2004). This section illustrates this with an example of one particular dropsonde profile. The observations showed differences of up to $8 \mathrm{~m} \mathrm{~s}^{-1}$ to the lidar profile in the same area (Fig. 4). All lidar-quality indices were well above the threshold values, and the winds that were calculated with different algorithms agreed among each other. A closer look at the dropsonde data revealed a lateral drift of the sonde away from the lidar scan into a strong updraft. Between a height of 1300 and $1000 \mathrm{~m}$ MSL, the fall rate decreased by $3 \mathrm{~m} \mathrm{~s}^{-1}$ (Fig. 4). The relative humidity between 750 and $1250 \mathrm{~m}$ MSL was $100 \%$ indicating a cloud. A shear layer with an increase of wind speeds by $32 \times 10^{-3} \mathrm{~s}^{-1}$ was located at the upper boundary of the cloud layer. This shear layer, indicating the top of the ABL, was about $500 \mathrm{~m}$ lower in the lidar data. Thus, we conclude that the dropsonde drifted into an overshooting convective updraft. The signal intensity of the lidar data in the surrounding of the dropsonde also indicated convective clouds above the mean height of the ABL (not shown). If this dropsonde (or radiosonde) would be the 

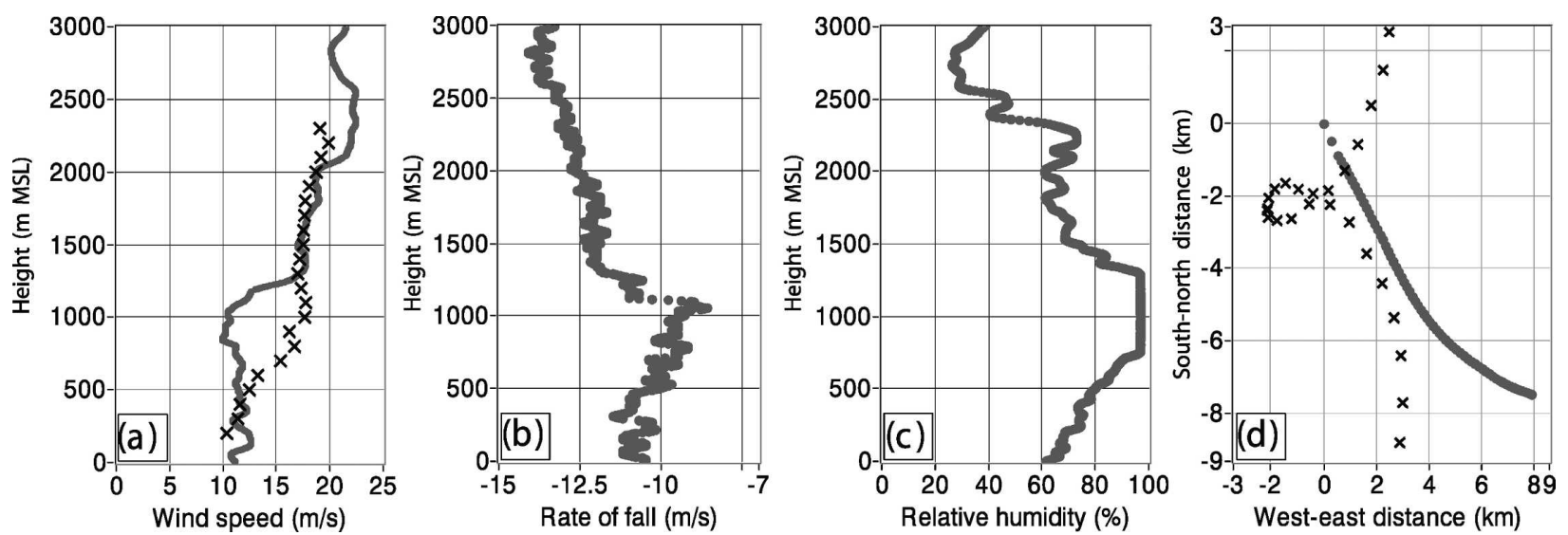

FIG. 4. (a) Wind speed, (b) rate of fall, (c) relative humidity, and (d) horizontal drift of a dropsonde launched at 1642 UTC 25 Nov 2003. The launch position $\left(56^{\circ} \mathrm{N}, 22^{\circ} \mathrm{W}\right)$ is the point of origin in (d). The corresponding lidar wind profile is plotted with $\mathrm{x}$ in (a), and the location of the lidar line-of-sight measurements used to calculate the wind profile are shown with $\mathrm{x}$ in (d). The dropsonde was launched at 1642 UTC 25 Nov 2003.

only one representing the meteorological data in a sensitive region, it could lead to temperature, wind, and humidity analysis errors, unless it is suspended by the quality checks of the assimilation procedure. The lidar data, in contrast, average over a larger area and, therefore, they are more representative for the wind in the region.

\section{Lidar measurements during A-TReC}

\section{a. Overview of the campaign}

The primary goal of A-TReC was to test the hypothesis that the forecast skill of extreme weather events over Europe and the east coast of the United States can be improved by adaptive observations (Richardson and Truscott 2004). Areas with expected heavy storms or severe precipitation were chosen as verification regions. Weather centers as ECMWF, Météo France, the Met Office, the National Centers for Environmental Prediction (NCEP), and the Naval Research Laboratory (NRL) performed the corresponding sensitivearea calculations. The European Meteorological Network (EUMETNET) composite observing system (EUCOS) ran the operation center at the Met Office, and the cases were selected among all of the participants.

Experience from the different A-TReC cases showed that the predicted sensitive areas are not only restricted to baroclinic zones (as may be anticipated based on dynamical arguments). They are also placed in areas that would not be obvious to a forecaster (Langland et al. 1999).

The DLR Falcon aircraft performed eight flights (an overview of the all measurements can be found online at http://www.pa.op.dlr.de/na-trec/) during A-TReC (Tables 3 and 4): five flights with targeted observations, two transfer flights, and one validation flight for the Advanced Synthetic Aperture Radar (ASAR) aboard the European environmental satellite Envisat. Dropsondes were only launched for the targeted observations, whereas the lidar was deployed during all flights. In total, the aircraft was operated for 28.5 flight hours, 49 dropsondes were launched, and 1612 wind profiles were measured by the Doppler lidar.

The lidar was operated in the A-TReC cases 12, 16, 18, 18_3, and 19 (Table 4). Cases 12, 16, 18, and 18_3 belong to events with expected strong surface winds or high precipitation in Europe. All cases were rated with a medium priority, because no one developed into a severe weather event. Although for case 19 sensitive areas were calculated east of Greenland, the actual flight track was designed to observe the flow response of Greenland during a tip jet event (Dörnbrack et al. 2004).

\section{b. The lidar observations}

The instrument proved to be capable of measuring winds under various synoptic conditions, although the environment above the northern Atlantic Ocean was not always favorable for coherent Doppler lidar operations. Except for sea-salt aerosols that were dispersed from the Atlantic Ocean, sources of atmospheric aerosol are located far away. Furthermore, the operation area was frequently covered by thick clouds, which cannot be penetrated by the lidar. Nevertheless, the lidar measured 25 wind values, on average, at every profile 
TABLE 4. Overview of the A-TReC measurements.

\begin{tabular}{|c|c|c|c|c|c|c|c|}
\hline Observation time & $\begin{array}{l}\text { Verification } \\
\text { time }\end{array}$ & $\begin{array}{c}\text { A-TReC } \\
\text { case number }\end{array}$ & $\begin{array}{l}\text { No. of } \\
\text { dropsondes }\end{array}$ & $\begin{array}{l}\text { No. } \\
\text { of lidar } \\
\text { profiles }\end{array}$ & $\begin{array}{c}\text { No. of } \\
\text { reliable } \\
\text { values }\end{array}$ & $\begin{array}{c}\text { Reliable } \\
\text { values/profile }\end{array}$ & $\begin{array}{c}\text { Flight } \\
\text { duration } \\
(\mathrm{h})\end{array}$ \\
\hline 0721-1053 UTC 14 Nov 2003 & & Transfer & & 237 & 9250 & 39 & 4.0 \\
\hline 1637-1931 UTC 15 Nov 2003 & $\begin{array}{l}1200 \text { UTC } \\
17 \text { Nov } 2003\end{array}$ & Case 12 & 10 & 193 & 3524 & 18 & 3.5 \\
\hline 1126-1319 UTC 18 Nov 2003 & & SAR comparison & & 146 & 3242 & 22 & 2.5 \\
\hline $\begin{array}{c}\text { 1356-1553, 1654-1948 } \\
\text { UTC } 20 \text { Nov } 2003\end{array}$ & $\begin{array}{l}0000 \text { UTC } \\
23 \text { Nov } 2003\end{array}$ & Case 16 & 10 & 210 & 2543 & 12 & 6.5 \\
\hline 1634-1935 UTC 22 Nov 2003 & $\begin{array}{l}0000 \text { UTC } \\
26 \text { Nov } 2003\end{array}$ & Case 18 & 12 & 205 & 4776 & 23 & 3.5 \\
\hline 1131-1443 UTC 24 Nov 2003 & $\begin{array}{l}1200 \text { UTC } \\
26 \text { Nov } 2003\end{array}$ & Case 19 & 4 & 283 & 8832 & 31 & 3.0 \\
\hline 1531-1826 UTC 25 Nov 2003 & $\begin{array}{l}0000 \text { UTC } \\
27 \text { Nov } 2003\end{array}$ & Case 18_3 & 13 & 205 & 6131 & 30 & 3.5 \\
\hline 0550-0737 UTC 28 Nov 2003 & & Transfer & & 133 & 1817 & 14 & 2.0 \\
\hline Total & & & 49 & 1612 & 40115 & 25 & 28.5 \\
\hline
\end{tabular}

with a vertical resolution of $100 \mathrm{~m}$ ( 25 values $=2500$ $\mathrm{m})$. The wind retrieval from lidar observations varied from an average of 12 to 39 values per profile (Table 4). Depending on meteorological conditions and the flight level, the coverage with wind data (reliable wind values divided by the amount of possible values) was in a range of $18 \%-67 \%$ (Table 3 ). Although the highest coverage with lidar wind measurements was reached on days with a low flight level (e.g., 18 November), the highest amount of wind data was obtained on flight altitudes between 7 and $12 \mathrm{~km}$ (flight levels FL 270320). Thus, a flight level in this range is suggested for future targeted operation, unless there is specific interest in low-level wind information.
The intensity of the backscatter signal increases with higher relative humidity. A swelling of the hygroscopic aerosols increases their particle size, and consequently increases the backscatter (Ackermann 1998). Because of these two characteristics of the heterodyne lidar, the best conditions for lidar measurements were convectively driven situations with a high relative humidity, but not too many or broken clouds (e.g., 14, 24, and 25 November).

Furthermore, the intensity of the backscatter that is received at the lidar decreases with the squared distance from the aircraft. Figure 5 illustrates the dependency on the distance and humidity for the lidar measurements during A-TreC, with the ratio of the number
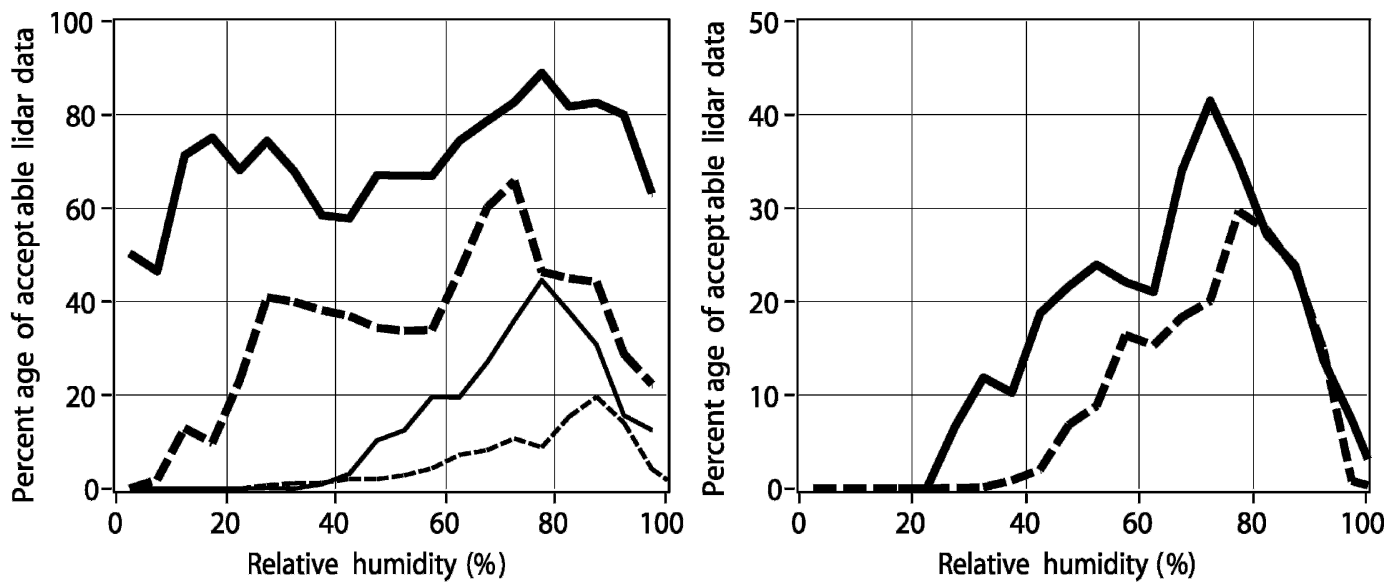

FIG. 5. (left) Percentage of lidar data with an acceptable error $\left(<1.5 \mathrm{~m} \mathrm{~s}^{-1}\right)$ on all flights during A-TReC for different classes of relative humidity. Lidar measurements at a distance of 500-2500 m from the aircraft (thick solid line), data at 2500-5000 $\mathrm{m}$ (thick dashed line), data at 5000-7500 $\mathrm{m}$ (thin solid line), and data at 7500-11 $000 \mathrm{~m}$ (thin dashed line) are shown. (right) Same as (left), but for data at a distance of 5000-11 $000 \mathrm{~m}$ from the aircraft. The solid line shows lidar data in the lowest $1000 \mathrm{~m}$ of the atmosphere (approximately the mean height of the ABL), and a dashed line shows lidar measurements above $1000 \mathrm{~m}$ MSL. 

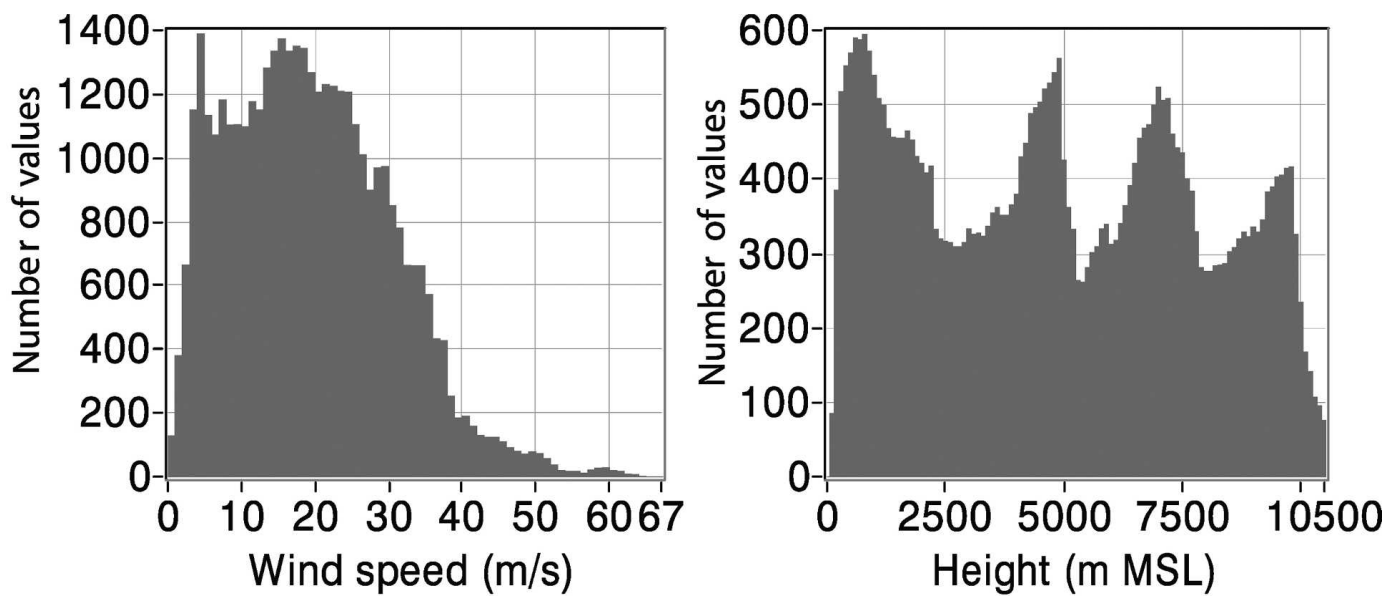

FIG. 6. Histogram of lidar measurements during A-TReC for (left) different wind speeds and (right) different heights.

of reliable measurements to that of possible measurements for different relative humidity. The comparison is based on the 6-hourly operational ECMWF analyses that are interpolated to the time and position of every lidar measurement. The analyses have a spectral resolution of 511 spherical harmonics $(\sim 40 \mathrm{~km})$ and 60 vertical levels

In the vicinity of the aircraft (distance $<2.5 \mathrm{~km}$ ), the dependency on humidity is low. The lidar measurements reach a coverage data of $60 \%-90 \%$ for a relative humidity above $10 \%$, and a coverage of $50 \%$ for a relative humidity below $10 \%$. For measurements at larger distances, the dependency on relative humidity increases gradually. The coverage of the lidar data increases with higher relative humidity (left panel in Fig. 5). Nearly no measurements exist at a distance of more than $5 \mathrm{~km}$ for a relative humidity below $40 \%$. For relative humidity around $80 \%$, in contrast, coverage of $40 \%$ is obtained at distances of 5-7.5 km. Despite the decrease of the lidar signal with the squared distance from the aircraft, the coverage at distances of more than 7.5 $\mathrm{km}$ is still $20 \%$ for a relative humidity around $90 \%$.

The backscatter intensity also depends on the aerosol concentration. Unfortunately, there are no measurements of aerosol concentrations, which could be compared to the lidar data. However, the aerosol concentration is generally higher in the $\mathrm{ABL}$ than in the free troposphere. The comparison of measurements within the lowest kilometer of the atmosphere (approximately the height of the $\mathrm{ABL}$ during $\mathrm{A}-\mathrm{TReC}$ ) to measurements above $1000 \mathrm{~m}$ MSL (right panel in Fig. 5) shows that the coverage is about $10 \%$ higher for measurements beneath $1000 \mathrm{~m}$ MSL than for measurements above for relative humidities of less than $80 \%$. At higher humidities, the coverage is about the same.
However, the stronger lidar signal in the $\mathrm{ABL}$ is not only caused by higher aerosol concentrations, but also by higher humidity in the ABL.

The observations with a minimum of acceptable measurements were made on a flight from Iceland to Greenland and backward. Only 12 values per profile could be measured, on average. On the second part of the flight an accumulation of the lidar signal of four scanner revolutions was necessary to derive a reliable wind. This decreased the horizontal resolution of the lidar profiles to $40 \mathrm{~km}$. The reasons for the weak lidar signal were a very low relative humidity caused by a descent of air to the lee of Greenland as well as advection of very clear air from the Arctic.

Figure 6 shows that the measured lidar winds range from 0 to $67 \mathrm{~m} \mathrm{~s}^{-1}$ with a mean wind speed of $20 \mathrm{~m} \mathrm{~s}^{-1}$. A maximum frequency lies between 15 and $20 \mathrm{~m} \mathrm{~s}^{-1}$, and another peak exists at $4 \mathrm{~m} \mathrm{~s}^{-1}$. The histogram of lidar measurements at different heights shows a maximum beneath $1300 \mathrm{~m}$ ASL, as expected, due a to higher aerosol concentration and relative humidity in the ABL. Further maxima were caused by the intense signal directly beneath the aircraft and the strong backscatter of clouds layers.

\section{c. The measurements on 25 November 2003}

In this section, we present one example of targeted lidar wind observations during A-TReC (case 18_3, Fig. 7). The observations were intended to improve the forecast of a low pressure system that is associated with heavy rain and strong winds in northern Europe at 1200 UTC 27 November 2003 (verification time). The flight on 25 November sampled a sensitive region above the Atlantic Ocean (Fig. 7a). On this particular day, all of the different sensitive area calculations showed sensi- 

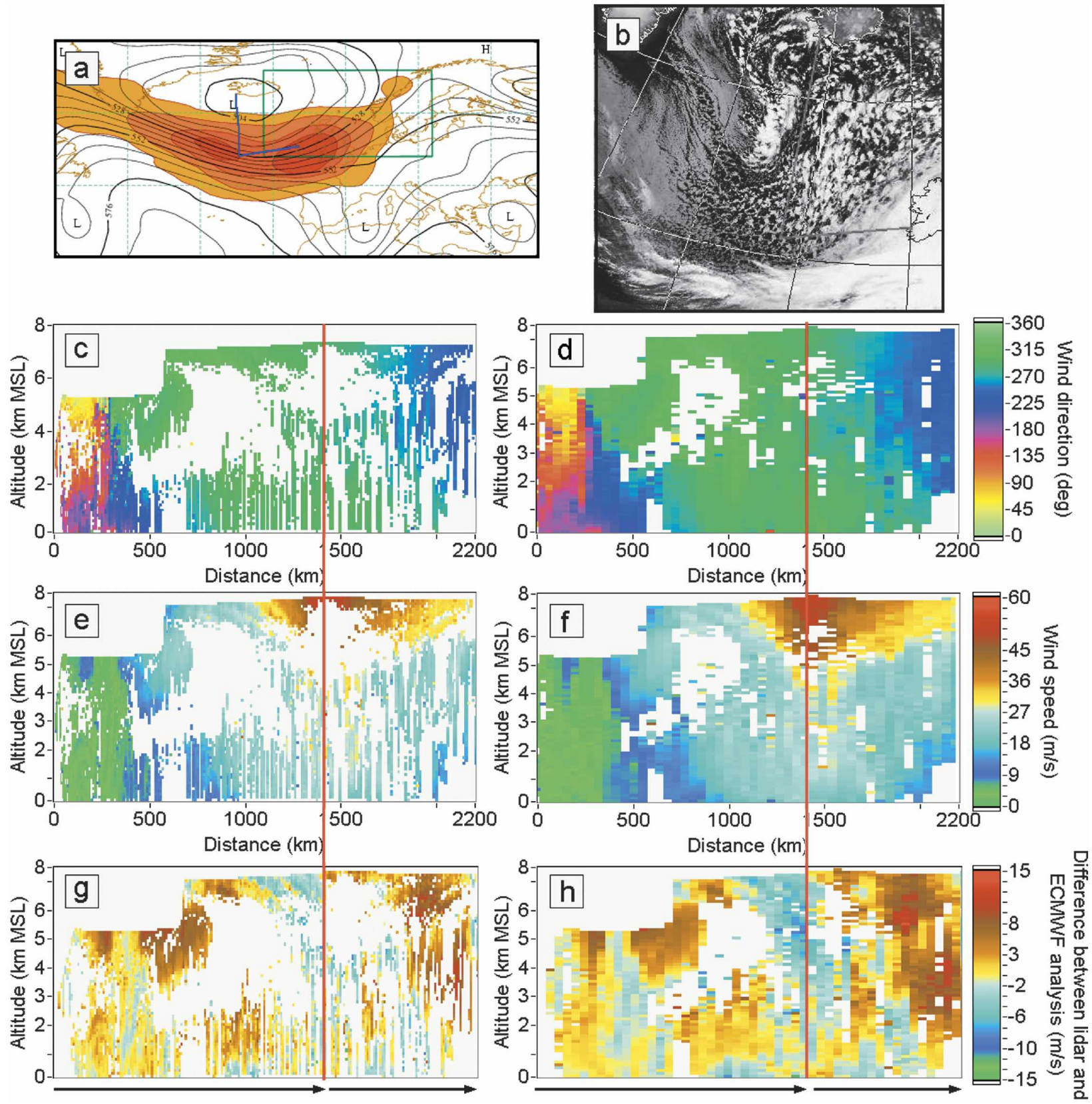

FIG. 7. (a) Flight track of the DLR Falcon (blue line) with underlying contours of the ECMWF forecast of 500-hPa geopotential height at 1800 UTC 25 Nov 2003 (targeting time), and color shadings show the ECMWF total energy singular vector summary map (dry T42) for the forecast in the verification region at 0000 UTC 27 Nov 2003 (image courtesy of ECMWF). Red areas (high energy) indicate high sensitivity. The verification region is marked by a rectangle. (b) AVHRR satellite image (channel 4) at 1521 UTC 25 Nov 2003 and the flight track are marked by a red line (image courtesy of the NERC Satellite Receiving Station, Dundee University, Scotland; information available online at http://www.sat.dundee.ac.uk/). Vertical cross sections of (c) and (d) lidar wind direction, (e) and (f) lidar wind speed, and $(\mathrm{g})$ and $(\mathrm{h})$ the difference of wind speeds between the lidar measurements and the ECMWF analysis as function of the distance along the flight track shown in Fig. 7. (c), (e), (g) Wind cross sections derived from one scan revolution of the lidar. (d), (f), (h) Wind cross sections from four scan revolutions. Red straight lines separate the north-south and the west-east segments of the cross sections. The analysis wind speeds were interpolated linearly in time and space to the location and time of the lidar measurements. 
tivity maxima in the diffluent part of the jet stream above and to the west of Ireland.

The DLR Falcon departed at 1530 UTC in Keflavik, Iceland, and flew southward into the jet stream. At $51^{\circ} \mathrm{N}$ the aircraft turned westward and continued along the jet axis to Ireland, where it landed at about 1830 UTC (Fig. 7). A low pressure system above Iceland caused wind speeds of less than $5 \mathrm{~m} \mathrm{~s}^{-1}$ in the beginning of the flight. As the airplane approached the jet, the wind speed increased gradually up to $67 \mathrm{~m} \mathrm{~s}^{-1}$. The synoptic conditions that are characterized by broken cumulus clouds and a high relative humidity were favorable for the lidar observation. On average, 30 wind values could be retrieved on every lidar profile, and the total coverage of the lidar measurements was $46 \%$ (Tables 3 and 4). This coverage increased to more than $80 \%$ if the wind was calculated from four scanner revolutions (96 LOS measurements, Fig. 7). However, the accumulation reduces the horizontal resolution of the resulting profiles to about $40 \mathrm{~km}$. The total number of wind values that are calculated with one scanner revolution is more than twice as high as that of the accumulated profiles. The maximum of wind information (high coverage and high horizontal resolution) is reached with a combination of both types, and it should be tested to assimilate both types, and a combination thereof, in NWP models.

Preliminary comparisons between the lidar measurements and the ECMWF operational analysis underline the need for additional and more representative wind measurements above the Atlantic Ocean. Figures $7 \mathrm{~g}$ and $7 \mathrm{~h}$ show the difference of wind speed on $25 \mathrm{No}-$ vember 2003 as one example of the comparison. The analysis wind speed was interpolated to the location and time of the lidar measurements in the same way as the relative humidity (section $4 \mathrm{~b}$ ). The horizontal resolution of the lidar winds that are derived from four scanner revolutions and the ECMWF analysis is roughly the same $(\sim 40 \mathrm{~km})$. Some uncertainties arise because of the linear time interpolation of the 6-hourly analysis fields because the temporal evolution of the wind field in between these analysis dates may be more complex.

The mean standard deviation of the difference on 25 November was $3.75 \mathrm{~m} \mathrm{~s}^{-1}$, and the last part of the cross section reveals differences of up to $\pm 15 \mathrm{~m} \mathrm{~s}^{-1}$ (Figs. $7 \mathrm{~g}$ and $7 \mathrm{~h}$ ), which seemed to be caused by a horizontal shift of the jet stream in the analysis. Differences of a similar magnitude were also observed on the other flights during A-TReC.

Because the observational error was determined to be $0.75-1 \mathrm{~m} \mathrm{~s}^{-1}$ (section 3 ) and the representativeness error of a line measurement through a $40-\mathrm{km}$ grid box is only around $0.14 \mathrm{~m} \mathrm{~s}^{-1}$, according to Frehlich and Sharman (2004), most of the difference seems to be a result of the error of the analysis. Tan and Andersson (2004) have reported wind errors of a similar magnitude in this region $\left(2.5-3.5 \mathrm{~m} \mathrm{~s}^{-1}\right)$. In this case, however, it is interesting that such a large error occurs even though our collocated dropsondes were assimilated in the operational analysis at ECMWF. A closer investigation of the analysis in the region where the large difference between the lidar and analysis wind speeds occurred showed that the two dropsondes did not have a large impact on the analysis. The root-mean-square (rms) difference between the analysis and the dropsonde observations (analysis departure) was $4.8 \mathrm{~m} \mathrm{~s}^{-1}$, and the rms difference between the background field and the dropsondes (background departure) was 5.7 $\mathrm{m} \mathrm{s}^{-1}$. This means that the rms difference between the measurements and model was only reduced by 0.9 $\mathrm{m} \mathrm{s}^{-1}$ with the assimilation of the dropsondes.

The large difference of the analysis and the measurements emphasizes the need for more representative wind measurements. The ECMWF assimilation scheme assumes a standard deviation of 2-3 $\mathrm{m} \mathrm{s}^{-1}$ (increasing with height) for dropsondes, because of the representativeness error of point measurements in a grid box. Wind lidar measurements, in contrast, could be assimilated with a smaller standard deviation, because they are more representative for the wind in a grid box. Consequently, they should have a higher impact on the analysis. Furthermore, the higher number of lidar observations compared to dropsonde measurements is likely to increase the impact.

On the other hand, the difference between the analysis and the dropsondes also illustrates that not only is the lack of measurements responsible for errors in the analysis fields, but also weaknesses of the current assimilation schemes (or errors in the first guess of NWP models).

\section{Conclusions and outlook}

Airborne Doppler lidar proved to be a reliable instrument for targeted wind measurements above the Atlantic Ocean under various synoptic conditions. Because of their small representativeness and observational errors, airborne wind lidar measurements have a high potential to reduce the analysis error of NWP models in data-sparse regions. Based on the characteristics of airborne wind lidar measurements that are derived in this study the impact on weather forecast will be evaluated through the assimilation of the observations in the ECMWF global model.

Despite the low aerosol concentration above the At- 
lantic Ocean, convectively driven situations with high relative humidity and frequent broken cloud coverage facilitated successful wind lidar operations during most flights. The coverage with reliable lidar wind measurements ranged from $18 \%$ to $67 \%$. We derived an empirical relation between the coverage of the lidar data, the relative humidity, and the distance from the aircraft. Altogether, 1612 one-scan-revolution wind profiles were collected during the flights. An accumulation of four scanner revolutions increases the coverage of the wind data by up to $50 \%$, but reduces their horizontal resolution by a factor of 4 . The impact of differently calculated wind profiles in the assimilation schemes of NWP models will be the subject of subsequent studies.

To assimilate wind lidar profiles in an NWP model, an observational error must be assigned to the wind measurements. For this purpose, a statistical comparison of 33 collocated lidar and dropsonde wind profiles was performed to derive a representative standard deviation of the wind lidar data. Advantageously, and in contrast to previous comparisons with dropsonde data, our comparison is based on a great variety of different synoptic situations. Assuming a variance originating from the observational error of the dropsondes and the representativeness (sample) error of about $0.5 \mathrm{~m}^{2} \mathrm{~s}^{-2}$, the mean standard deviation of the wind lidar observations is $0.75-1.0 \mathrm{~m} \mathrm{~s}^{-1}$. This observational error is higher than the observational error of dropsondes $\left(\sim 0.5 \mathrm{~m} \mathrm{~s}^{-1}\right)$. However, the representativeness error dominates the total error in the data assimilation. According to Frehlich and Sharman (2004), the representativeness error of a line measurement through a $40-\mathrm{km}$ grid box is $\sim 0.15 \mathrm{~m} \mathrm{~s}^{-1}$. In contrast, the representativeness error of a point measurement (e.g., a dropsonde) in the same box is about $1.5 \mathrm{~m} \mathrm{~s}^{-1}$. In consequence, we suggest that a total error of about $1 \mathrm{~m} \mathrm{~s}^{-1}$ is assigned to the lidar measurements in the data assimilation system of the current ECMWF model (T511). This is substantially smaller than the error that is usually assigned to dropsondes $\left(\sim 2-3 \mathrm{~m} \mathrm{~s}^{-1}\right)$.

The magnitude of the difference between lidar and dropsonde winds was correlated with selected quality indices derived in this study. For high-quality wind lidar data the standard deviation decreased to values below $0.5 \mathrm{~m} \mathrm{~s}^{-1}$. Based on this intercomparison, individual standard deviations were assigned to the different classes of the quality indices. Furthermore, we evaluated the accuracy and coverage of lidar wind data that were derived with two different algorithms: one inverts the LOS velocities to a $3 \mathrm{D}$ wind, and the other one is based on the maximum function of the accumulated spectra (Smalikho 2003).

A better knowledge of the initial state through ad- vanced observations is a key to improve the forecast skill of NWP models. Our lidar observations showed deviations up to $\pm 15 \mathrm{~m} \mathrm{~s}^{-1}$ to the operational ECMWF analyses. These differences did not only occur in topographically influenced regions close to Greenland but also above the Atlantic Ocean, as exemplified in this paper with a case study. On one side, the large differences emphasize the importance and need for wind measurements in data-sparse regions. On the other hand, further impact studies with the wind lidar data and the other adaptive A-TReC observations are necessary to investigate their influence on the analyzed and forecasted fields.

Last, but not least, our study—based on real atmospheric observations-will constitute an experimental basis for developing quality-controlled assimilation schemes for Doppler wind profiles. Hopefully, the current paper and our planned work shed some light on the beneficial use of next-generation spaceborne instruments as the Doppler wind lidar of the Atmospheric Dynamics Mission (ADM) of the European Space Agency (ESA 1999).

Acknowledgments. The campaign was partly funded by EUCOS and by the Institut für Physik der Atmosphäre of DLR. The authors want to thank its director, Prof. Ulrich Schumann, for his personal support of the campaign. Prof. Georg Mayr from the University Innsbruck contributed several fruitful ideas to the study. The professional operation of the DLR flight crew under difficult weather conditions and their flexibility in the flight operations and planning is very much appreciated. Further thanks are due to Rudolf Simmet, the technician of the 2- $\mu \mathrm{m}$ lidar, and to Martin Großhauser, who assisted in analyzing the lidar data. Haraldur Ólafsson contributed his knowledge of the local synoptic environment in the investigation area to the planning of the aircraft operations. Last, but not least, thanks are due to Carla Cardinali, who provided information about the data assimilation at ECMWF and the tools to calculate analysis and background departures.

\section{REFERENCES}

Ackermann, J., 1998: The extinction-to-backscatter ratio of tropospheric aerosol: A numerical study. J. Atmos. Oceanic Technol., 15, 1043-1050.

Bastin, S., P. Drobinski, A. Dabas, P. Delville, O. Reitebuch, and C. Werner, 2005: Impact of the Rhône and Durance Valleys on sea-breeze circulation in the Marseille area. Atmos. Res., 74, 303-328.

Browning, K. A., and R. Wexler, 1968: The determination of kinematic properties of a wind field using Doppler radar. $J$. Appl. Meteor., 7, 105-113. 
Dörnbrack, A., M. Weissmann, S. Rahm, R. Simmet, O. Reitebuch, R. Busen, and H. Ólafsson, 2004: Wind lidar observations in the lee of Greenland. Extended Abstracts, 11th Conf. on Mountain Meteorology and the Annual Mesoscale Alpine Programme (MAP Meeting), Bartlett, NH, Amer. Meteor. Soc., CD-ROM, P2.6.

Drobinski, P., and Coauthors, 2005: The Summer Mistral at the exit of the Rhône Valley. Quart. J. Roy. Meteor. Soc., 131, 353-375.

ESA, 1999: The four candidate Earth explorer core missions: Atmospheric dynamics mission. ESA Rep. for Mission Selection SP 1233 (4), 157 pp.

Frehlich, R., 2001: Errors from space-based Doppler lidar measurements: Definition, performance, and verification. J. Atmos. Oceanic Technol., 18, 1749-1772.

— , and R. Sharman, 2004: Estimates of turbulence from numerical weather prediction model output with applications to turbulence diagnosis and data assimilation. Mon. Wea. Rev., 132, 2308-2324.

Henderson, S. W., P. J. M. Suni, C. P. Hale, S. M. Hannon, J. R. Magee, D. L. Bruns, and E. H. Yuen, 1993: Coherent laser radar at $2 \mu \mathrm{m}$ using solid-state lasers. IEEE Trans. Geosci. Remote Sens., 31, 4-15.

Joly, A., and Coauthors, 1997: The Fronts and Atlantic StormTrack Experiment (FASTEX): Scientific objectives and experimental design. Bull. Amer. Meteor. Soc., 78, 1917-1940.

- and Coauthors, 1999: Overview of the field phase of the Fronts and Atlantic Storm-Track Experiment (FASTEX) project. Quart. J. Roy. Meteor. Soc., 125, 3131-3163.

Köpp, F., S. Rahm, and I. Smalikho, 2004: Characterization of aircraft wake vortices by $2-\mu \mathrm{m}$ pulsed Doppler lidar. J. Atmos. Oceanic Technol., 21, 194-206.

Langland, R. H., and Coauthors, 1999: The North Pacific Experiment (NORPEX-98): Targeted observations for improved North American weather forecasts. Bull. Amer. Meteor. Soc., 80, 1363-1384.

Mapes, B. E., P. E. Ciesielski, and R. H. Johnson, 2003: Sampling errors in rawinsonde-array budgets. J. Atmos. Sci., 60, 26972714.

Marseille, G. J., and F. Bouttier, 2001: Climatologies of sensitive areas for short-term forecast errors over Europe-A
EUMETNET-EUCOS study. ECMWF Tech. Memo. 334, $50 \mathrm{pp}$.

Montani, A., A. J. Thorpe, R. Buizza, and P. Undén, 1999: Forecast skill of the ECMWF model using targeted observations during FASTEX. Quart. J. Roy. Meteor. Soc., 125, 3219-3240.

Rahm, S., R. Simmet, and M. Wirth, 2003: Airborne two micron coherent lidar wind profiles. Proc. 12th Coherent Laser Radar Conf., Bar Harbor, ME, 94-97.

Reitebuch, O., C. Werner, I. Leike, P. Deville, P. Flamant, A. Cress, and D. Engelbart, 2001: Experimental validation of wind profiling performed by the airborne $10-\mu \mathrm{m}$ heterodyne Doppler lidar, WIND. J. Atmos. Oceanic Technol., 18, 13311344.

_ H. Volkert, C. Werner, A. Dabas, P. Delville, P. Drobinski, P. H. Flamant, and E. Richard, 2003: Determination of air flow across the Alpine ridge by a combination of airborne Doppler lidar, routine radio-sounding, and numerical simulation. Quart. J. Roy. Meteor. Soc., 129, 715-728.

Richardson, D. S., and B. Truscott, 2004: The 2003 Atlantic THORPEX Regional Campaign (TReC). Proc. Symp. on Forecasting the Weather and Climate of the Atmosphere and Ocean, Seattle, WA, Amer. Meteor. Soc., CD-ROM, J7.1.

Smalikho, I., 2003: Techniques of wind vector estimation from data measured with a scanning coherent Doppler lidar. $J$. Atmos. Oceanic Technol., 20, 276-291.

Szunyogh, I., Z. Toth, R. E. Morss, S. J. Majumdar, B. J. Etherton, and C. H. Bishop, 2000: The effect of targeted dropsonde observations during the 1999 Winter Storm Reconnaissance program. Mon. Wea. Rev., 128, 3520-3537.

— - - A. V. Zimin, S. J. Majumdar, and A. Persson, 2002: Propagation of the effect of targeted observations: The 2000 Winter Storm Reconnaissance program. Mon. Wea. Rev., 130, 1144-1165.

Tan, D. G. H., and E. Andersson, 2004: Simulation of the yield and accuracy of wind profile measurements from the Atmospheric Dynamics Mission (ADM-Aeolus). ECMWF Tech. Memo. 431, 31 pp.

Weissmann, M., F. J. Braun, L. Gantner, G. J. Mayr, S. Rahm, and O. Reitebuch, 2005: The Alpine mountain-plain circulation: Airborne Doppler lidar measurements and numerical simulations. Mon. Wea. Rev., 133, 3095-3109. 